\title{
Total correction of type I truncus arteriosus in a 6-month-old infant ${ }^{1}$
}

\author{
A. Singh, M. de Leval, and J. Stark \\ From the Thoracic Unit, Hospital for Sick Children, Great Ormond Street, London
}

\begin{abstract}
A successful correction of type I truncus arteriosus using a $12 \mathrm{~mm}$ 'dacron' conduit containing a porcine aortic valve (Hancock) between the right ventricle and the pulmonary artery in a 6-month-old infant is reported. The rationale for the treatment of truncus arteriosus in infancy is discussed.
\end{abstract}

Truncus arteriosus is a relatively rare congenital cardiac anomaly (Keith, Rowe, and Vlad, 1967). The defect is characterized by the presence of a single, large arterial trunk originating from the base of the heart. It is accompanied by a ventricular septal defect immediately subjacent to the truncus or sometimes by a complete absence of ventricular septum. Collett and Edwards (1949) have classified truncus arteriosus according to the site of origin of the pulmonary arteries arising from a single arterial trunk. This classification remains clinically useful though patients with their type IV are more correctly grouped with patients with pulmonary atresia.

McGoon, Rastelli, and Ongley (1968) first reported a successful correction of this anomaly in a $5 \frac{1}{2}$-year-old boy. Since then their experience has grown to include $7 \mathrm{I}$ corrected patients with 6I per cent survival (de Leval et al., 1974). Only a few successful corrections have been reported recently in infants (Cartmill, 1974; Girinath, 1973; Kirklin, 1973a). We wish to report the case of a 6-month-old infant weighing $4.7 \mathrm{~kg}$ who underwent a successful one-stage total correction of type I truncus arteriosus.

\section{Case report}

The patient, a girl, was born after a normal pregnancy and delivery. Her birthweight was $3.35 \mathrm{~kg}$. A heart murmur was noted at birth. At the age of 3 months she developed mild tachypnoea and was admitted to another hospital. Heart failure was diagnosed; the child was given digitalis, and then referred to our unit for further investigation and treatment.

${ }^{1}$ This work was supported in part by a grant from the British Heart Foundation.
On admission she weighed $3.94 \mathrm{~kg}$. Examination showed rapid, shallow respiration $(60 / \mathrm{min})$, a bounding pulse (140/min), and a blood pressure of $110 / 30 \mathrm{mmHg}$ (14.6/4 $\mathrm{kPa}$ ). A right ventricular heave with $3 / 4$ systolic murmur was heard over the praecordium. The second heart sound was loud and single. Bilateral crepitations were heard over the lung field and both the liver and spleen were enlarged and palpable $4 \mathrm{~cm}$ below the costal margin. The electrocardiogram showed a prolonged PR interval, $P$ pulmonale, axis +90 , and biventricular hypertrophy. $X$-ray examination of the chest showed cardiomegaly and pulmonary plethora. She underwent cardiac catheterization (Table) and angiocardiography (Fig. I) which revealed type I truncus arteriosus, a high single ventricular septal defect, patent foramen ovale, and a right aortic arch. Treatment of the cardiac failure was increased and the child improved. She was discharged home on digoxin, frusemide, and potassium.

Follow-up examination at 4 months of age showed slight cyanosis, shortness of breath after feeding, and enlarged spleen and liver. She was admitted to hospital and kept on full treatment for cardiac failure without much improvement. It was, therefore, decided to proceed with early correction. Owing to the presence of atypical antibodies and anti-M titre in her blood compatible blood was not available. The operation had to be delayed until she was 6 months of age. The aorta and the venae cavae were cannulated. Conventional cardiopulmonary bypass was established using a disc oxygenator primed with fresh heparinized blood. The left ventricle was vented. The repair was performed with intermittent cross-clamping of the aorta at $25^{\circ} \mathrm{C}$ nasopharyngeal temperature. The pulmonary artery was detached from the truncus. The resulting defect in the aorta was closed in two layers using $4-0$ Prolene. A longitudinal right ventriculotomy was made and a high subaortic ventricular septal defect was closed with a 'teflon' patch using a 4-O Prolene running stitch so that the left ventricle emptied into the aorta. The right atrium was then opened and a patent foramen ovale sutured. The continuity between the main pulmonary artery and right 
TABLE Intracardiac pressures at catheterization and at operation

\begin{tabular}{lcclc}
\hline Site & $\begin{array}{l}\text { Blood pressure } \\
\text { At 3 months } \\
m m H g\end{array}$ & $k P a$ & $\begin{array}{l}\text { At operation } \\
m m H g\end{array}$ & $k P a$ \\
\hline RA (mean) & 5 & 0.7 & - & - \\
RV & $100^{\prime} 12^{\star}$ & $13.3 / 1.6$ & 70 & 9.3 \\
MPA & $80 / 3^{\star}$ & $10.6 / 5.1$ & RPA-30/14 & $-4 / 1.9$ \\
LA (mean) & 6 & 0.8 & 13 & 1.7 \\
LV & $110 / 12$ & $14.6 / 1.6$ & 95 & 12.6 \\
Aorta & $110 / 25$ & $14.6 / 3.3$ & 90 & 12.0 \\
\hline
\end{tabular}

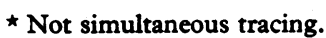

$R A=$ right atrium; $R V=$ right ventricle; $M P A=$ main pulmonary artery; $L A=$ left atrium; $L V=$ left ventricle.

ventricle was restored using a No. 12 prosthetic 'dacron' conduit containing a porcine aortic valve (Hancock prosthesis) (Fig. 2). The conduit was placed to the left of the aorta. The patient was rewarmed and air was evacuated via the left ventricular vent and aortic needle vent. Cardiopulmonary bypass was discontinued without difficulty. The pressures were measured (Table). Though the right ventricular pressure was raised cardiac output was adequate. There was no shurit murmur, therefore the chest was closed in a routine manner.

A nasotracheal tube was inserted and the patient was

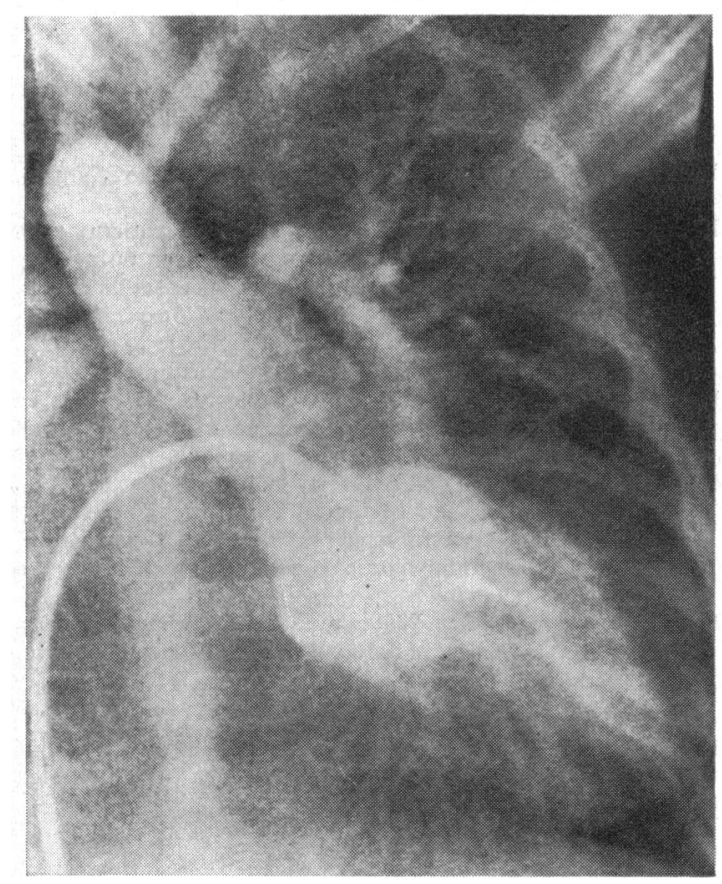

FIG. I Angiocardium showing both pulmonary arteries arising from the back of the ascending aorta (type I truncus arteriosus). ventilated on a volume controlled respirator (Engström). Her haemodynamics remained stable throughout the postoperative period. Because of some pulmonary congestion she was restarted on digoxin, frusemide, and potassium. Ventilation was gradually discontinued. She was extubated on the fifth postoperative day, and discharged on the nineteenth postoperative day. She was last seen six months after operation and was progressing well. Examination showed a grade 2/5 systolic murmur over the praecordium and a chest radiograph showed a slightly enlarged heart. The digoxin and diuretics were discontinued.

\section{Discussion}

About 80 per cent of all patients with persistent truncus arteriosus die during the first year of life if untreated (Keith et al., 1967). The most common cause of death is congestive heart failure, and many survivors develop pulmonary vascular disease (Mair et al., 1974). Because of the high mortality and also because of the frequent development of pulmonary vascular disease surgical treatment should be offered early. Pulmonary artery banding has been used as a palliative treatment for truncus arteriosus in infancy, but the reported results are poor (Stark et al., 1969; Behrendt et al., 1974).

Good results from early correction of various complex congenital heart defects reported from several centres (Barratt-Boyes, Neutze, and Harris, 1973; de Leval and Stark, 1974; Kirklin, 1973a) have encouraged us to attempt the total repair of truncus arteriosus in a 6-month-old baby. This operation may still be considered palliative, because the conduit may have to be replaced later by a larger one. Nevertheless, the unsatisfactory results of pulmonary artery banding and the possible difficulties encountered at the time of subsequent correction and recent reports by Cartmill (1974), Kirklin (1973b), and Girinath (1973) persuaded us that early total repair is a logical approach. We intend to pursue this policy in the future. 


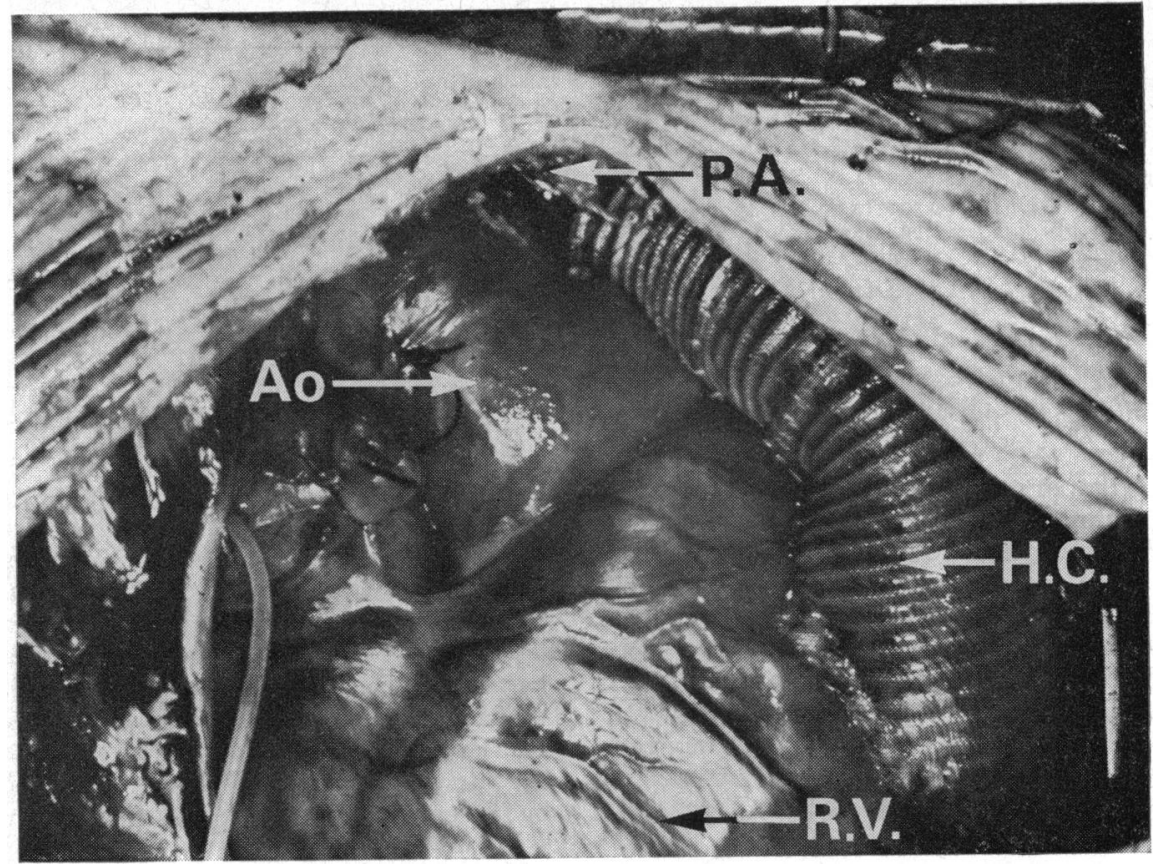

FIG. 2 Operative view showing conduit (Hancock) on the left side of the aorta. HC=Hancock conduit; $A o=$ aorta; $R V=$ right ventricle; $P A=$ pulmonary artery.

\section{References}

Barratt-Boyes, B. G., Neutze, J. M., and Harris, E. A. (1973). Heart Disease in Infancy: Diagnosis and Surgical Treatment. Churchill Livingstone, Edinburgh.

Behrendt, D. M., Kirsh, M. M., Stern, A., Sigmann, J., Perry, B., and Sloan, H. B. (1974). The surgical therapy for pulmonary artery-right ventricular discontinuity. Annals of Thoracic Surgery, 18, 122.

Cartmill, T. B. (1974). Communication at the International Meeting on Pediatric and Cardiac Surgery in Taormina.

Collett, R. W., and Edwards, J. E. (1949). Persistent truncus arteriosus: a classification according to anatomic types. Surgical Clinics of North America, 29, 1245.

de Leval, M. R., McGoon, D. C., Wallace, R. B., Danielson, G. K., and Mair, D. D. (1974). Management of truncal valvular regurgitation. Annals of Surgery, 180, 427.

de Leval, M., and Stark, J. (1974). Open heart surgery in the first year of life. Acta Chirurgica Belgica, 73, 48r.

Girinath, M. R. (1973). Case presentation: truncus arteriosus: repair with homograft reconstruction in infancy. In Heart Disease in Infancy: Diagnosis and Surgical Treatment, p. 234. Ed. by B. G. Barratt-Boyes, J. M. Neutze, and E. A. Harris. Churchill Livingstone, Edinburgh.

Keith, J. D., Rowe, R. D., and Vlad, P. (1967). Persistent truncus arteriosus including aortic pulmonary septal defect. In Heart Disease in Infancy and Childhood, 2nd ed., p. 770. Macmillan, New York.

Kirklin, J. W. (1973a). Advances in Cardiovascular Surgery. Grune and Stratton, New York.

Kirklin, J. W. (1973b). Surgical treatment of patients with absence of direct anatomic continuity between pulmonary arterial system and the heart and ventricular septal defect. In Heart Disease in Infancy. Diagnosis and Surgical Treatment, p. 21 I. Ed. by B. G. Barratt-Boyes, J. M. Neutze, and E. A. Harris. Churchill Livingstone, Edinburgh.

McGoon, D. C., Rastelli, G. C., and Ongley, P. A. (I968). An operation for the correction of truncus arteriosus. fournal of the American Medical Association, 205, 69.

Mair, D. D., Ritter, D. G., Davis, G. D., Wallace, R. B., Danielson, G. K., and McGoon, D. C. (1974). Selection of patients with truncus arteriosus for surgical correction: anatomic and hemodynamic considerations. Circulation, 49, 144 .

Stark, J., Aberdeen, E., Waterston, D. J., Bonham-Carter, R. E., and Tynan, M. (1969). Pulmonary artery constriction (banding): a report of 146 cases. Surgery, $65,808$.

Requests for reprints to Dr. J. Stark, Thoracic Unit, The Hospital for Sick Children, Great Ormond Street, London WCIN $3 \mathrm{JH}$. 